\title{
DRIVER ATTITUDE TOWARDS TRAFFIC SAFETY VIOLATIONS AND RISK TAKING BEHAVIOUR IN KUMASI: THE GENDER AND AGE DIMENSION
}

\author{
Millicent Awialie Akaateba', Richard Amoh-Gyimah ${ }^{2}$ \\ ${ }^{1}$ Department of Planning and Management, FPLM, University for Development Studies Wa, Ghana \\ ${ }^{2}$ CSIR-Building and Road Research Institute, Kumasi, Ghana
}

Received 10 May 2013; accepted 14 November 2013

\begin{abstract}
This study investigated age and gender related differences in drivers' self-reported attitudes towards traffic violations and the gains or motivations influencing the violation of traffic laws in Kumasi. A total of 285 drivers were sampled for the study drawn from local bus terminals and taxi stations, work places, universities and other gatherings within the Kumasi Metropolis. Both self-completed questionnaires and interviews were used for the study. The results of the study showed that gender and age have significant influence on attitudes towards the commission of traffic violations though not by a large margin. The perceived gains associated with traffic violations also to a large extent influence driver attitude towards traffic violation in Kumasi with men being more motivated by the perceived gains to be derived from traffic violations than females. Neither significant nor great age differences were found regarding the extent to which perceived gains influenced the commission of traffic violations. Plausible explanations and implications for these findings to traffic safety campaigns as well as methodological issues are discussed. Suggestions for further research are also highlighted.
\end{abstract}

Keywords: traffic safety, driver attitudes, traffic violations, perceived gains, age, gender.

\section{Introduction}

Road traffic accidents have become a major public health concern in both developed and developing countries alike as they constitute a major cause of fatalities globally. In Ghana, traffic accidents are an even greater issue as they are among the leading causes of death and injuries (Afukaar et al., 2003). An estimated 1,800 people die annually while 14,500 people are injured through accidents on the country's roads. In 2010, about 2,125 people died through road accidents whilst 14,008 were injured. Pedestrians and bus occupants account for over $65 \%$ of traffic fatalities whilst people aged 16-45 constitute about $60 \%$ of all road fatalities in Ghana from 2000 to 2009 (NRSC, 2011). The socio-economic cost of road accidents is estimated at $1.6 \%$ of Ghana's Gross Domestic Product (GDP) (Ackaah et al., 2008).

The World Health Organization (WHO) estimated that without the effective implementation of efficient counter measures, an $80 \%$ increase in road traffic accidents should be expected in low- and middle-income countries during the period 2000 to 2020 of which Ghana is a part (Peden et al., 2004).

\footnotetext{
${ }^{1}$ Corresponding author: makaateba@uds.edu.gh
} 
Driving safety has become a priority issue in developing countries in view of the increasing motorisation levels. This calls for greater focus on driver attitudes and behaviour towards traffic safety. Driving safety is affected by various factors, which together determine the level of traffic safety or risk. Such factors include driver characteristics, road layout, the design of the car and weather condition. However, most road accidents are attributed to 'human factor' most especially to road safety violations (Gras et al., 2004; Sullman et al., 2002; Parker et al., 1995). There is documented evidence indicating that driver behaviour plays a key role in traffic safety as it is important in traffic accident prevention (Parker et al., 1995; Evans, 1996). Attitudes have been revealed to be significant predictors of driver behaviour in high-income countries and have also been identified to indirectly affect involvement in traffic accidents (Iversen and Rundmo, 2004; Iversen, 2004; Rakauskas et al., 2007). In Ghana however, studies have revealed that attitudes are an insignificant predictor of risky driving behaviour (Lund, 2006; Lund and Rundmo, 2009). Lund and Rundmo (2009) however revealed that people in Ghana and other low income countries reported more willingness to take risks both in road traffic and in other general settings.

The influence of socio-demographic variables such as gender, age, educational levels and personality variables on driver behaviour has been widely established by several studies in high income countries (Nordfjaern et al., 2010, 2012; Oltedal and Rundmo, 2006; Lund and Rundmo, 2009; Yagil, 1998; Deery, 1999). Similar studies in low income countries have indicated that male gender and low age influence risk constructs, attitudes and driving behaviour in similar patterns (Afukaar et al., 2003; Odero et al., 1997). These studies have therefore proven successful in relating demographic variables (gender and age) to driver attitude and risk taking behaviour in relation to road safety.

Although information on demographic characteristics of drivers may appear not very productive from a practical perspective if the aim of the road safety intervention is not to change behaviour, such information could prove useful in defining target groups so that road safety campaigns could be more target specific (Forward, 2009a). Similarly, studying driver attitudes towards traffic regulations is particularly important in developing countries as compliance to road traffic regulations affect not only the drivers' safety but that of passengers and pedestrians. In Ghana, traffic safety campaigns have focused exclusively on the entire population with few/no targeted campaigns at specific groups of drivers. Therefore, identifying the gender and age differences in driver attitudes towards traffic regulations and traffic violations will provide relevant information towards more target-specific and effective road safety campaigns in the country.

\section{Theoretical Background}

\subsection{Driving Attitudes, Behaviour and Traffic Safety Violations}

Attitudes, risk perception and behaviour have been found to be related to each other and to traffic safety within traffic psychology. This attitude-behaviourtraffic safety relationship has been an old phenomenon that has been widely analysed with theories such as the Theory of 
Reasoned Action and the Theory of Planned Behaviour (TPB) in developed countries (Parker et al., 1992; Iversen and Rundmo, 2004; Eiksund, 2009; Forward, 2009b). Attitudes have often been defined to mean tendencies to evaluate an object with some degree of favour or disfavor, expressed in affective, cognitive or behavioral responses (Eagly and Chaiken, 1993). Violations consist of a complex category of errors and are categorized as behaviors (either deliberate or unintentional) that deviate from accepted procedures, standards, and rules (Stanton and Salmon, 2009). Various studies conducted in high income countries (Parker et al., 1992, 1995; Iversen and Rundmo, 2004; Eiksund, 2009; Stanton and Salmon, 2009; Nordfjærn et al., 2011) indicated that attitudes towards traffic safety are significant predictors of driver behaviours. Using results from a Driver Behaviour Questionnaire, Parker et al. (1995) showed that self reported driver violations are good predictors of driver involvement in accidents. Forward (2009b) revealed that the TPB behaviour was able to predict drivers' intention to commit two driving violations: speeding in an urban area and dangerous overtaking.

Iversen and Rundmo (2004) analysed the relationship between attitudes, risky behaviour and accident involvement and concluded that attitudes contribute to the prediction of behaviour. They found that risky behaviour had an influence on both involvement in near accidents and involvement in accidents, and explained a $21 \%$ of the total variance. In a study on the differences in attitudes to traffic safety and driver behaviour in urban and rural Norway, Eiksund (2009) found that among other variables such as culture and demographic characteristics, attitudes to driving explained significant amounts of variation in driver behaviour in both urban and rural areas.

It is worth noting however that most studies that investigated the behaviourattitude-traffic safety relationships using the TPB were carried out in high income countries which put the cross-cultural applicability of the TPB in low income countries in doubt. Studies by Lund and Rundmo (2009) revealed that attitudes towards road traffic safety were significant predictors of road traffic behaviours in Norway but not in Ghana. Nordfjærn et al. (2011) also indicated that risk concepts and attitudes to driving explained a significant proportion of behaviour variance in Norway, Russia and India but the model was poorly fitted in the low-income Sub-Saharan Africa countries of Ghana, Tanzania and Uganda. A weaker relationship between driver attitudes towards road traffic safety and behaviour in urban Iran was also identified by Yunesian et al. (2008). This low applicability therefore means that low income countries may need to initiate their own effective countermeasures in attitude campaigns related to road safety other than import western measures. However, before this is done, it will be important to conduct further studies in these countries. Such studies should not cover too large and varied groups but rather be directed at specific groups of drivers.

\subsection{Gender and Age Variability in Traffic Attitudes and Violations and Crash Involvement}

Various studies have demonstrated that demographic variables (gender and age) have an influence on driver attitudes, traffic violations and involvement in crashes. 
Nordfjærn et al. (2010) found that gender and age have significant influence on differences in driver attitudes and behaviour in both rural and urban areas. Males and young adolescents are seen to have less favourable attitudes towards driving safety, less sensitivity to risk and underestimate the probability and severity of risks caused by traffic conditions compared to females and the elderly. Morgan and Mannering (2011) established that female drivers of 45 years and above had had slightly lower no-injury probabilities on both wet and snow/ice surfaces compared to dry surfaces. Older males and older females also had an increased likelihood of severe injuries on wet or snow/ice surfaces compared to younger male drivers who had a decreased probability of severe injuries on wet and snow/ice surfaces relative to dry surfaces.

In order to account for the human factorenvironment-infrastructure interaction in crashes, Russo et al. (2013) calibrated safety performance functions (SPFs) to predict the injury crash frequency over traffic exposure (injury crash rate) on two-lane rural roads in the Southern Italy for three main crash types (head-on/side collisions, rear-end collisions, single vehicle run-off-road crash). The results of their study revealed that when males and females are combined, females in both curved dry road surfaces and curved wet road surfaces during both day and night time are more cautious with single vehicle crash circumstances than males. They also found females to be more cautious under wet-curved road surfaces at daytime with head-on/side collisions than males. This indicates that females are more careful and have lower risk taking attitudes than males. In terms of age, Russo et al. (2013) again found that under wet-curved road surfaces in the night, drivers within the ages of 18-
40 years have a higher risk of single-vehicle crashes whilst those within the ages of 20-45 years have higher risks for rear-end collisions in dry road surfaces at night at a tangent segment scenario.

Farah (2011) examined age and gender differences in overtaking manoeuvres on two-lane rural highways and found differences in gender and age with respect to frequency of overtaking, overtaking time duration, following distances, overtaking speed and critical overtaking gaps. Young males were found to have shorter overtaking times, higher overtaking speeds and closer following distances than old males and females. Vlahogianni and Golias (2012) also observed differences in behavior between young males and female drivers during overtaking. Vlahogianni (2013) identified gender as a critical factor that influences the duration of overtaking in two lane highways. In the case of back-to-lane maneuver, male drivers were observed to take longer time to return to their original lane than female drivers. In a gap acceptance study, Yan et al. (2007) revealed that older drivers tend to accept larger gaps than younger drivers by using larger gaps to make left turns, keep higher car following distances and turn the steering wheel more slowly. Similarly, in terms of gender, male drivers accept smaller gaps than female drivers suggesting that older drivers and female drivers are more conservative. Alexander et al. (2002) also established that older drivers as well as female drivers require larger gaps than younger drivers and male drivers.

In examining the relationship between personality traits and driving styles, Poo and Ledesma (2013) in an alternative 5-factor model found that different patterns of personality are associated with different 
driving styles particularly with respect to gender and age. They found that impulsive sensation seeking and aggression-hostility were the main predictors for risky driving and these were more predominant among males than females. Younger age groups were also observed to have significant impulsive sensation seeking and risky driving. Vardaki and Yannis (2013) investigated drivers' selfreported behaviors and attitudes to driving violations and perceived acceptance of violation countermeasures and identified males to constitute a clear majority of drivers who commit traffic violations compared to females. Female drivers were found to have strong views in support of traffic violation countermeasures and toward compliance with traffic rules than males. Forward (2010) showed that age and mileage added to the prediction of speeding in an urban area with young people more likely to violate regulations than older people.

In investigating the effect of gender on driver behaviour and accident involvement, Bener and Crundall (2008) revealed significant higher accident rates among male drivers as compared to female drivers with females reporting a higher number of driving violations and lapses than males. Kontogiannis et al. (2002) found that highway-code and aggressive violations among Greek drivers differ significantly as a function of age and gender with younger drivers and males more likely to report engaging in such violations than are older drivers and females. Romano et al. (2012) also identified male drivers to be more likely to be involved in impaired driving and alcohol-related crashes than females. Iversen and Rundmo (2004) revealed that there was a tendency for younger respondents and male respondents to show more negative attitudes towards safety and engage in more 'non-ideal' behaviours in traffic than others do. Yagil (1998) investigated gender and age-related differences in attitudes towards traffic laws and traffic violations and found out that the male drivers and younger drivers reported a lower level normative motivation to comply with traffic laws and a higher commission of traffic violations compared to females and older drivers. Deery (1999) found that younger drivers violate the law more often than older drivers.

Lund and Rundmo (2009) examined cultural differences in risk perception and attitudes towards traffic safety and risk taking behaviour in Ghana and Norway and found adolescents to be more willing to take risks in traffic compared to older adults in both Norway and Ghana. Ghanaian adolescents were also found to be less sensitive to risks, and more willing to take risks compared to adults. In terms of gender, the study found that Norwegian males perceived risks as lower compared to Norwegian females but no significant differences in gender were found among Ghanaians. In a similar study on cultural and socio-demographic predictors of car accident involvement in Norway, Ghana, Tanzania and Uganda conducted by Nordfjærn et al. (2012), it was revealed that male gender, predicted higher accident involvement in all the studied countries but more particularly in Norway and Tanzania.

These studies have been confirmed by statistics from the National Road Safety Commission in Ghana which reveal that males and young people are overrepresented in road traffic casualties. This overrepresentation of males and young adults in Ghana can be explained by the fact that Ghana and other developing countries generally have very high young populations 
due to lower life expectancies coupled with males being the most dominant driver group. The overrepresentation of male drivers in Ghana therefore has the tendency to increase traffic risk since males are known to hold less favourable attitudes and lower risk perceptions than females. It is in the light of this that the main aim of this study is to investigate how gender and age differences influence driver attitude towards specific traffic violations and risk taking behaviour in Kumasi. Although cross cultural comparative studies have been conducted to investigate these differences in Ghana as a whole (Lund, 2006; Lund and Rundmo, 2009; Nordfjærn et al., 2011, 2012), at the time of writing this paper, no geographic specific study has been conducted on this topic in Kumasi (the second largest city in Ghana). Results for this study will therefore suggest the specific target group attitudes and behaviour that injury intervention programmes should focus on. Russo et al. (2013) and Ulleberg and Rundmo (2003) posited that injury prevention programmes in developing countries are more likely to be successful when they are targeted at specific risk groups by a bottom-up approach rather than targeting the entire population.

\section{Methodology}

\subsection{Questionnaire Design}

Based on relevant validated variables from previous studies (Yagil, 1998, Iversen, 2004; Iversen and Rundmo, 2004) for measuring attitudes towards traffic safety and traffic regulations contained in the Ghana Highway Code, a total of 24 items relevant to the Ghanaian context were adapted and included in the questionnaire. The 24 items were grouped into three categories to measure driver attitudes related to traffic safety. The first category measures drivers' attitudes towards traffic violations through the frequency of involvement in traffic violations using 10 items/statements. Respondents were asked to assess how frequently they carried out each of the activities during the previous year Responses to the statements were scored against a four-point Likert-scale with the options 'never', 'occasionally' 'frequently' and 'always'. The second category measured gains relating to traffic violations using a total of six motives which can influence the commission of a traffic violation. The extent to which each potential gain/motive can increase the likelihood of a driver committing a traffic violation was evaluated using a five point Likert-scale with the options as 'to a very small extent', 'to a small extent', 'not applicable to me', 'to a large extent' and 'to a very large extent'. The third category measures drivers' sense of obligation to obey traffic laws using eight statements. A five-point evaluation scale was applied, and the response options were: 'absolutely wrong', 'wrong', 'neutral', 'correct' and 'absolutely correct'.

The questionnaire was pretested on 20 drivers in the Adum area of the Kumasi Metropolis for reliability evaluation using Cronbach's alpha. The Cronbach's alpha is one of the most widely used reliability measures and for any basic research; a reliability value of $>0.7$ is considered satisfactory (Churchill, 1991; Litwin, 1995). The first two of the three sections of the questionnaire passed the reliability test with Cronbach's alpha of 0.757 and 0.740 respectively thus exhibiting a high internal consistency. The last section of the questionnaire however failed the test with a Cronbach's alpha of 0.348 . This section was therefore excluded from the final questionnaire for the study. 


\subsection{Respondents}

The population for the study was drivers in the Kumasi Metropolis, the second largest city in Ghana. The respondents were gotten from local bus terminals and taxi stations, work places, universities and other gatherings within the Kumasi Metropolis. Research Assistants approached respondents from these places to ensure that various categories of drivers from different social strata were included in the sample. In situations where respondents were literate, the questionnaires were self completed by them but where the respondents were illiterate; they were interviewed over the questionnaire by the research assistants. At the end of a weeklong survey and evaluation of the questionnaires, a total of 285 completed questionnaires were accepted for analysis. The data were analyzed using frequencies tables, one-way ANOVA and the Bonferroni Post Hoc analysis modules of the SPSS statistical package.

\section{Empirical Results}

\subsection{Description of Respondents}

Of the 285 respondents, $88.8 \%$ were males and $11.2 \%$ were females. As required by law that any person below age 18 cannot drive, it was found that no respondent was below 18 years. Majority of the respondents (47.4\%) were between the ages of 31 to 40 . Only $10.9 \%$ of the respondents were over 50 years of age. A further analysis shows half (50.2\%) of male respondents fall within the age group of 31 to 40 whereas majority of the females (43.8\%) fall between the ages of 18-30 years. The over representation of male respondents in the sample is a reflection of the general male dominance in the driver population of Ghana.

\subsection{Frequency of Violation of Traffic Laws}

The statistical results (means and standard deviations) for the 10 items on the selfreported violation of traffic laws suggest that majority of drivers reported 'occasionally' violating traffic laws. The Total Mean for these items in Table 1 is 3.47. The most frequently violated traffic offence reported by respondents is the failure to wear the seat belt which had the lowest mean of 3.03 whilst driving under the influence of alcohol was the least reported frequently violated traffic law as shown in Table 1 (Mean $=3.9)$.

Table 1

Extent to which Drivers Violate Traffic Law

\begin{tabular}{lll}
\hline Statement: To what extent do these traffic violations apply to you & Mean (SD) & Rank \\
\hline 1. Overtaking when prohibited & $3.57(0.56)$ & $3 \mathrm{a}$ \\
2. Using the mobile phone when driving & $3.17(0.61)$ & 9 \\
3. Failing to comply with a traffic light signal & $3.63(0.60)$ & $2 \mathrm{a}$ \\
4. Failing to wear the seat belt & $3.03(0.86)$ & 10 \\
5. Getting off the road to bypass a traffic jam & $3.54(0.60)$ & $4 \mathrm{a}$ \\
6. Driving too close to the car in front & $3.32(0.61)$ & 8 \\
7. Not stopping at pedestrian crossing when pedestrians are waiting to cross & $3.53(0.56)$ & $5 \mathrm{a}$ \\
8. Driving under the influence of alcohol & $3.96(0.18)$ & $1 \mathrm{a}$ \\
9. Stopping at undesignated areas to pick passengers & $3.48(0.64)$ & 6 \\
10. Exceeding the speed limit & $3.44(0.60)$ & 7 \\
Total Mean & 3.47 & \\
\hline
\end{tabular}

Likert scale scores: 1 = always; 4 = never.

${ }^{a}$ The five highest-ranking statements. 


\subsection{Gains Associated with Traffic Violations}

The results of the study presented in Table 2 indicate that perceived gains associated with traffic violations to a large extent influence respondents' attitudes towards traffic violations. This was largely associated with such gains as adding interest to driving, feeling in control and avoiding other drivers' anger as shown in Table 2.

Table 2

Motivations for Traffic Violations

\begin{tabular}{llc}
\hline Statement: To what extent would these gains influence you to violate traffic laws & Mean (SD) & Rank \\
\hline 1. Arriving quickly & $3.79(1.07)$ & 6 \\
2. Adding interest to driving & $4.31(0.91)$ & $1^{\mathrm{a}}$ \\
3. Feeling in control & $4.26(0.97)$ & $2^{\mathrm{a}}$ \\
4. Getting ahead of other drivers & $3.99(1.13)$ & 4 \\
5. Achieving comfort/satisfaction & $3.87(1.33)$ & 5 \\
6. Avoiding other drivers' anger & $4.18(1.11)$ & $3^{\mathrm{a}}$ \\
Total Mean & 4.07 &
\end{tabular}

Likert scale scores: 1 = to a very small extent; $5=$ to a very large extent.

${ }^{a}$ The three highest-ranking statements

\subsection{Gender Differences in the Violation of Traffic Laws}

Table 3 presents the statistical results obtained from the one-way ANOVA and the Bonferroni Post Hoc analysis conducted for males and females on the self-reported frequency of the commission of traffic violations. The statistical tests showed significant gender effect with regard to traffic violations involving failing to comply with a traffic light signal $(F=5.92, p<$ $0.05)$; failing to wear the seat belt $(F=5.98$, $p<0.05)$; getting off the road to bypass a traffic jam $(F=9.66, p<0.01)$ and driving too close to the car in front $(F=5.56, p$ $<0.05$ ) with females reporting a lower frequency of violating these laws compared to males. The means in Table 3 indicate that females have a lower frequency of violating traffic laws than males $(M=3.63$ for females compared with $M=3.43$ for males). Table 4 which presents the gains motivating drivers' commission of traffic violations between gender indicate that males largely associate potential gains with the tendency to commit a driving violation than females do $(M=$ 4.02 and $M=4.07$, respectively) except with regard to motivations involving 'getting ahead of other drivers'. Gender differences in perceived gains associated with traffic violations were significant for gains relating to adding interest to driving and getting ahead of other drivers. 
Table 3

Frequency of Driver's Violation of Traffic Laws between Gender

\begin{tabular}{|c|c|c|c|c|c|}
\hline Gender & $\begin{array}{l}\text { Male } \\
(\mathrm{a})^{\mathrm{a}}\end{array}$ & $\begin{array}{l}\text { Female } \\
\text { (b) }{ }^{\mathrm{a}}\end{array}$ & F & $P$ & Bonferroni \\
\hline \multicolumn{6}{|l|}{$\begin{array}{l}\text { Statement: To what extent do these traffic } \\
\text { violations apply to you }\end{array}$} \\
\hline 1. Overtaking when prohibited & 3.55 & 3.75 & 3.63 & 0.058 & \\
\hline 2. Using the mobile phone when driving & 3.17 & 3.19 & 0.04 & 0.852 & \\
\hline 3. Failing to comply with a traffic light signal & 3.60 & 3.88 & 5.92 & $0.016^{*}$ & $a \& b$ \\
\hline 4. Failing to wear the seat belt & 2.98 & 3.38 & 5.98 & $0.015^{*}$ & $a \& b$ \\
\hline 5. Getting off the road to bypass a traffic jam & 3.50 & 3.84 & 9.66 & $0.002^{* *}$ & $a \& b$ \\
\hline 6. Driving too close to the car in front & 3.29 & 3.56 & 5.56 & $0.019^{*}$ & $\mathrm{a} \& \mathrm{~b}$ \\
\hline $\begin{array}{l}\text { 7. Not stopping at pedestrian crossing } \\
\text { when pedestrians are waiting to cross }\end{array}$ & 3.52 & 3.66 & 1.74 & 0.188 & \\
\hline 8. Driving under the influence of alcohol & 3.96 & 4.0 & 1.31 & 0.254 & \\
\hline 9. Stopping at undesignated areas to pick passengers & 3.47 & 3.56 & 0.54 & 0.465 & \\
\hline 10. Exceeding the speed limit & 3.43 & 3.53 & 0.80 & 0.373 & \\
\hline Total Mean & 3.43 & 3.63 & & & \\
\hline
\end{tabular}

Likert scale scores: 1 = always; $4=$ never.

${ }^{a}$ All data in these columns are means.

${ }^{*} P<0.05$.

${ }^{* *} P<0.01$.

\section{Table 4}

Gains Motivating Drivers' Commission of Traffic Violations between Gender

$\begin{array}{llllll}\text { Gender } & \begin{array}{l}\text { Male } \\ (\mathrm{a})^{\mathrm{a}}\end{array} & \begin{array}{l}\text { Female } \\ (\mathrm{b})^{\mathrm{a}}\end{array} & F & P & \text { Bonferroni }\end{array}$

Statement: To what extent would these gains influence you to violate traffic laws

$\begin{array}{llllll}\text { 1. Arriving quickly } & 3.79 & 3.79 & 0.01 & 0.947 & \\ \text { 2. Adding interest to driving } & 4.36 & 3.94 & 6.17 & 0.014^{*} \quad \mathrm{a} \& \mathrm{~b} \\ \text { 3. Feeling in control } & 4.27 & 4.16 & 0.41 & 0.524 & \\ \text { 4. Getting ahead of other drivers } & 3.91 & 4.56 & 9.69 & 0.002^{*} & \mathrm{a} \& \mathrm{~b} \\ \text { 5. Achieving comfort/satisfaction } & 3.90 & 3.59 & 1.52 & 0.219 & \\ \text { 6. Avoiding other drivers' anger } & 4.19 & 4.09 & 0.23 & 0.633 & \\ \text { Total Mean } & 4.07 & 40.2 & & & \end{array}$

Likert scale scores: $1=$ to a very small extent; $5=$ to a very large extent.

${ }^{a}$ All data in these columns are means.

${ }^{*} P<0.05$.

${ }^{* *} P<0.01$.

\subsection{Age Differences in the Violation of Traffic Laws}

Besides gender differences, the statistical results of the study indicate significant age effect on the frequency of violation of some traffic laws in Ghana. Significant gender differences regarding using the mobile phone when driving $(F=2.77, p<0.05)$; failing to wear the seat belt $(F=4.33, p<0.01)$; 
getting off the road to bypass a traffic jam $(F=5.15, p<0.01)$; not stopping at pedestrian crossing $(F=3.77, p<0.05)$ and stopping at undesignated areas to pick passengers $(F=3.77, p<0.05)$ were found among respondents. Respondents within the younger age groups of $18-30(M=3.46)$ and 31-40 reported a higher frequency (3.38) of violating traffic laws than older respondents between the ages of 41-50 $(M=3.58)$ or above 50 years $(M=3.65)$ as shown in
Table 6. There were however no significant differences among the age groups with reference to perceived gains that influence driving violations as shown on Table 6. A cross analysis of age and gender with regard to the violation of traffic laws in Table 5 indicate that younger males of age 31-40 reported the highest frequency of violating traffic laws among all the respondents whilst females of all age groups reported a lower frequency of violating traffic laws compared to males.

\section{Table 5}

Age and Gender Differences in Frequency of Violating Traffic Laws

\begin{tabular}{lllll}
\hline Age group & Gender & & & \\
& Male & & Female & \\
& No. of Respondents & Mean & No. of Respondents & Mean \\
\hline $18-30$ & 72 & 3.44 & 14 & 3.58 \\
$31-40$ & 127 & 3.36 & 8 & 3.60 \\
$41-50$ & 28 & 3.58 & 5 & 3.60 \\
Above 50 & 26 & 3.60 & 5 & 3.88 \\
\hline
\end{tabular}

\section{Table 6}

Frequency of Drivers' Violation of Traffic Laws between Age Groups

\begin{tabular}{|c|c|c|c|c|c|c|c|}
\hline Age Groups & $\begin{array}{l}18-30 \\
\text { (a)a }\end{array}$ & $\begin{array}{l}31-40 \\
\text { (b)a }\end{array}$ & $\begin{array}{l}41-50 \\
\text { (c)a }\end{array}$ & $\begin{array}{l}>50 \\
(d) a\end{array}$ & F & $P$ & Bonferroni \\
\hline \multicolumn{8}{|l|}{$\begin{array}{l}\text { Statement: To what extent do these traffic } \\
\text { violations apply to you }\end{array}$} \\
\hline 1. Overtaking when prohibited & 3.58 & 3.51 & 3.70 & 3.65 & 1.20 & 0.311 & \\
\hline 2. Using the mobile phone when driving & 3.13 & 3.10 & 3.36 & 3.35 & 2.77 & $0.042^{*}$ & \\
\hline 3. Failing to comply with a traffic light signal & 3.69 & 3.54 & 3.79 & 3.37 & 2.17 & 0.092 & \\
\hline 4. Failing to wear the seat belt & 3.08 & 2.86 & 3.30 & 3.32 & 4.33 & $0.005^{* *}$ & $\mathrm{~b} \& \mathrm{c}, \mathrm{b} \& \mathrm{~d}$ \\
\hline 5. Getting off the road to bypass a traffic jam & 3.53 & 3.44 & 3.58 & 3.90 & 5.15 & $0.002^{* *}$ & $a \& d, b \& d$ \\
\hline 6. Driving too close to the car in front & 3.29 & 3.26 & 3.48 & 3.51 & 2.36 & 0.071 & \\
\hline $\begin{array}{l}\text { 7. Not stopping at pedestrian crossing } \\
\text { when pedestrians are waiting to cross }\end{array}$ & 3.45 & 3.50 & 3.63 & 3.77 & 3.06 & $0.029^{*}$ & $a \& d, b \& d$ \\
\hline 8. Driving under the influence of alcohol & 3.97 & 3.99 & 3.94 & 3.90 & 1.931 & 0.125 & \\
\hline $\begin{array}{l}\text { 9. Stopping at undesignated areas to pick } \\
\text { passengers }\end{array}$ & 3.52 & 3.39 & 3.48 & 3.77 & 3.20 & $0.024^{*}$ & $b \& d$ \\
\hline 10. Exceeding the speed limit & 3.40 & 3.42 & 3.52 & 3.58 & 0.936 & 0.424 & \\
\hline Total Mean & 3.46 & 3.38 & 3.58 & 3.65 & & & \\
\hline
\end{tabular}

Likert scale scores: $1=$ always; $4=$ never.

${ }^{a}$ All data in these columns are means. ${ }^{*} P<0.05 .{ }^{* *} P<0.01$. 
Table 7

Gains Motivating Drivers' Commission of Traffic Violations between Age Groups

\begin{tabular}{llllllll}
\hline Age Groups & $\begin{array}{l}18-30 \\
(\mathrm{a}) \mathrm{a}\end{array}$ & $\begin{array}{l}31-40 \\
(\mathrm{~b}) \mathrm{a}\end{array}$ & $\begin{array}{l}41-50 \\
(\mathrm{c}) \mathrm{a}\end{array}$ & $\begin{array}{l}>50 \\
\text { (d)a }\end{array}$ & $F$ & $P$ & Bonferroni \\
$\begin{array}{l}\text { Statement: To what extent would these } \\
\text { gains influence you to violate traffic laws }\end{array}$ & & & & & & & \\
\hline 1. Arriving quickly & 3.76 & 3.86 & 3.52 & 3.90 & 1.07 & 0.363 \\
2. Adding interest to driving & 4.31 & 4.32 & 4.39 & 4.19 & 0.26 & 0.852 \\
3. Feeling in control & 4.15 & 4.30 & 4.33 & 4.32 & 0.52 & 0.666 \\
4. Getting ahead of other drivers & 3.93 & 3.99 & 3.88 & 4.23 & 0.64 & 0.593 \\
5. Achieving comfort/satisfaction & 3.76 & 4.03 & 3.61 & 3.74 & 1.39 & 0.245 \\
6. Avoiding other drivers' anger & 4.02 & 4.29 & 4.21 & 4.13 & 1.03 & 0.381 \\
Total Mean & 3.99 & 4.13 & 3.99 & 4.09 & & \\
\hline
\end{tabular}

Likert scale scores: 1 = to a very small extent; 5 = to a very large extent.

${ }^{a}$ All data in these columns are means.

${ }^{*} P<0.05$.

${ }^{* *} P<0.01$.

\section{Discussion and Conclusion}

This study investigated age and gender related differences in drivers' self-reported frequency of violation of traffic laws and the gains and motivations associated with the violation of traffic laws in Ghana. The study provides some insights and expands the evidence base for the hypothesized phenomenon of the over representation of young males in traffic violations and risky driving behaviour. Although the overall results of the study revealed a general lower reported frequency of violation of traffic laws by respondents (i.e. occasional violations), the study also showed that there were small, yet significant, differences between gender and age on the one hand and the frequency of traffic safety violations on the other hand. This was particularly true for attitudes relating to the frequency of violation of traffic laws on failing to comply with a traffic light signal; failing to wear the seat belt; getting off the road to bypass a traffic jam; and driving too close to the car in front. Males in the study (especially younger males) reported a relatively higher frequency of violation of traffic laws than females (see Table 3). This means that males have a higher tendency of not complying with traffic laws than females in Ghana. This corroborates findings from various studies such as Vlahogianni (2013); Vardaki and Yannis (2013); Farah, (2011); Romano et al. (2012); Nordfjærn et al. (2012; 2010); Iversen and Rundmo (2004); Afukaar et al. (2003); Yagil (1998); Odero et al. (1997) and Harre et al. (1996).

A plausible explanation for the gender differences in the frequency of violation of traffic laws can be linked to the cultural upbringing, the Ghanaian socialisation process and traditional gender roles. Whilst females are trained and brought up to be obedient, submissive, passive and risk averse, males are raised up to be independent, take risks, speak out and challenge the status quo. These differences in the socialisation process and women's traditional gender roles according to Simon and Corbett (1996) are likely to have translated into the general willingness of females to unquestionably comply with traffic laws. Males also tend 
to be over-confident of their driving ability than females; as a result, they tend to selectively comply with traffic laws which increase their frequency of violation of traffic laws.

In line with the findings of other studies by Vlahogianni and Golias (2012); Farah (2011); Forward (2010); Yan et al. (2007); Kontogiannis et al. (2002); Parker et al. (1995), Yagil (1998), Deery (1999), Afukaar et al. (2003); Iversen and Rundmo (2004), results of the study revealed that drivers' age has significant effect on the frequency of commission of traffic violations. From the study, younger drivers report a more often violation of traffic laws than old drivers. The difference is especially pronounced and significant for traffic violations relating to using the mobile phone when driving, failing to wear the seat belt, getting off the road to bypass a traffic jam and stopping at undesignated areas to pick passengers. The major issue with young drivers' particularly young male drivers is that the majority of them do not regard driving to be a dangerous activity to them and even for the few who do, the danger and risk involved is not perceived to be directly applicable to the individual at a personal level. This combined with their pronounced optimism and over rating of their driving skills results in young drivers more often than old drivers violating traffic laws. Due to the need for sensation seeking by younger drivers, they are also more often prone to the violation of traffic laws which they feel are restrictive to their sensation seeking behaviours.

General results from the study indicate that perceived gains associated with traffic violations to a large extent influence driver attitude towards traffic violation in Kumasi especially for perceived gains relating to adding interest to driving, feeling in control and avoiding other drivers' anger. This implies that the rational-choice theory that describes driving behaviour as a product of reasoned calculations is very relevant and applicable in Kumasi. This finding agrees with Wallén Warner and Åberg (2008) who found that behavioural beliefs such as getting to the destination quicker and making driving more fun significantly influence intentions to commit traffic violations. Similarly, Parker et al. (1992) found that drivers who sped in an urban area were motivated by such gains as taking them to their destination quicker and being more comfortable. In reference to gender differences, results of the study revealed that males are more motivated by the perceived gains to be derived from traffic violations than females. This affirms Berkowitz (1993) assertion that men appear seemingly more prone to violating some traffic regulations in order to achieve their aims.

A relevant implication that can be drawn from the study is to recognise that demographic variables of gender and age have a major role to play in traffic safety campaigns in Ghana. There is abounding evidence indicating that young males are more prone to traffic violations and at a high risk of involvement in road traffic crashes. This study provides some results that support this conclusion and attribute this problem to socialisation processes, exaggeration of driving skills and sensation seeking behaviour of young male drivers. This indicates that there is the need to move away from traffic safety campaigns that tend to cover varied and large populations to campaigns that will influence high risks groups in a more efficient way. A more feasible intervention for addressing traffic law violations would be to target young male drivers' attitude towards traffic 
safety particularly their risk-taking attitudes which are strongly related to risky driving behaviour in safety campaigns.

It is suggested that traffic safety messages should be of a high sensation value to be able to elicit sensory and arousal responses from high sensation-seeking young male drivers rather than being too general and untargeted. The results of the study also suggest that, there is the need to develop effective and strong measures that will be capable of countering the optimism of young male drivers regarding their driving abilities. It is important to design traffic safety demonstrations on the limits of young males driving skill in terms of accident avoidance. It is also important to identify specific attitudes associated with specific risky behaviours of young drivers and develop specific traffic safety interventions to influence these attitudes and behaviours. A more effective strategy will also be to adopt a participatory approach to reducing the risk taking behaviours of young drivers. This will mean allowing young drivers themselves to find out the need for attitudinal and behavioural change and how the change process should take place. This has proved to be an effective strategy in safety programmes for professional drivers (Gregersen et al., 1996).

In conclusion, the results of this study present some evidence that suggest that demographic variables of gender and age have some influence on driver attitudes towards traffic violations and risky driving behaviours among drivers in Kumasi. However, not all the gender and age differences were significant, indicating perhaps that not all traffic violations were influenced by demographic variables. The study focused only on age and gender differences in the frequency of traffic law violations and motivations for traffic violations. However other demographic variables such as educational level, marital status, occupation/income level, form of driver education, extent of driving among others may have an influence on traffic violations and risky driving behaviours. Therefore further research on these variables is recommended.

Another major limitation of the study hinges on the use of self-reported driver attitudes to traffic violations. The validity of self-reports by drivers is unknown and this can affect the results of the study. Some drivers may choose to present themselves as drivers who frequently commit traffic violations whilst others may have the tendency to impress by giving ideal self-descriptions to make the best possible impression whilst another group may simply regard such information as sensitive and may choose not to respond to attitudes which are socially undesirable. Albeit these weaknesses, self-reported driver attitudes are very useful as they reduce the time and money cost associated with other alternative approaches such as use of simulators which are expensive to acquire in developing countries like Ghana. Selfreports also have the added advantage of not putting drivers under strict observation which may compel drivers to behave in a more ideal and disciplined manner which is totally different from the drivers' normal driving behaviour. Lajunen and Summala (2003) in their study concluded that social desirability had a relatively small impact in traffic safety studies. Notwithstanding the identified limitations of the present study, it still has some implications for safety research and traffic safety campaigns in Ghana. The study concludes with a suggestion that there is the need to apply a number of targeted road 
safety campaigns that are tailored to certain risky driving behaviours and common traffic law violations among young male drivers in Ghana.

\section{References}

Ackaah, W.; Afukaar, F.K.; Agyeman, W.; Debrah, E.K. 2008. Socio-Economic Cost of Road Traffic Accidents in Ghana, Journal of Building and Road Research Institute, 11: 39-44.

Afukaar, F.K.; Antwi, P.; Amaah, S.O. 2003. Pattern of road traffic injuries in Ghana: implications for control, Injury Control and Safety Promotion. DOI: http://dx.doi. org/10.1076/icsp.10.1.69.14107, 10(1-2): 69-76.

Alexander, J.; Barham, P.; Black, I. 2002. Factors influencing the probability of an incident at a junction: results from an interactive driving simulator, Accident Analysis and Prevention. DOI: http://dx.doi.org/10.1016/ S0001-4575(01)00078-1, 34(6): 779-792.

Bener, A.; Crundall, D. 2008. Role of gender and driver behaviour in road traffic crashes, International Journal of Crashworthiness. DOI: http://dx.doi. org/10.1080/13588260801942684, 13(3): 331-336.

Berkowitz, L. 1993. Aggression: Its causes, consequences, and control. New York: McGraw-Hill.

Churchill, G.A. 1991. Marketing Research: Methodological Foundation, $5^{\text {th }}$ Ed. The Dryden Press, New York.

Deery, H.A. 1999. Hazard and risk perception among young novice drivers, Journal of Safety Research. DOI: http://dx.doi.org/10.1016/S0022-4375(99)00018-3, 30(4): 225-236.

Eagly, A.H.; Chaiken, S. 1993. The Psychology of Attitudes. Harcourt Brace, Jovanovich Fort Worth, TX.

Eiksund, S. 2009. A geographical perspective on driving attitudes and behaviour among young adults in urban and rural Norway, Safety Science. DOI: http://dx.doi. org/10.1016/j.ssci.2008.07.034, 47(4): 529-536.

Evans, L. 1996. Comment: the dominant role of driver behaviour in traffic safety, American Journal of Public Health, 86(6): 784-785.

Farah, H. 2011. Age and gender differences in overtaking manoeuvres on two-lane rural highways, Transportation Research Record. DOI: http://dx.doi.org/10.3141/224804, 2248: 30-37.

Forward, S.E. 2009a. An assessment of what motivates road violations, Transportation Research Part F: Traffic Psychology and Behaviour. DOI: http://dx.doi. org/10.1016/j.trf.2008.12.003, 12(3): 225-234.

Forward, S.E. 2009b. The theory of planned behaviour: The role of descriptive norms and past behaviour in the prediction of drivers' intentions to violate, Transportation Research Part F: Traffic Psychology and Behaviour. DOI: http://dx.doi.org/10.1016/j.trf.2008.12.002, 12(3): 198-207.

Forward, S.E. 2010. Intention to speed in a rural area: Reasoned but not reasonable, Transportation Research Part F: Traffic Psychology and Behaviour. DOI: http:// dx.doi.org/10.1016/j.trf.2010.04.002, 13(4): 223-232 .

Gras, M.E.; Cunill, M.; Sullman, J.M.; Planes, M.; Aymerich, M. 2004. Self-reported aberrant driving behaviour in a sample of Spanish drivers. Available from Internet: <http://www.psychology.nottingham. ac.uk/IAAPdiv13/ICTTP2004papers2/Individual\%20 Differences/GrasB.pdf $>$.

Gregersen, N.P.; Bremher, B.; More'n, B. 1996. Road safety improvement in large companies. An experimental comparison of different measures, Accident Analysis and Prevention. DOI: http://dx.doi.org/10.1016/00014575(95)00060-7, 28(3): 297-306.

Harre, N.; Field, J.; Kirkwood, B. 1996. Gender Differences and Areas of Common Concern in the 
Driving Behaviours and Attitudes of Adolescents, Journal of Safety Research. DOI: http://dx.doi.org/10.1016/00224375(96)00013-8, 27(3): 163-173.

Iversen, H.H. 2004. Risk-taking attitudes and risky driving behaviour, Transportation Research Part F: Traffic Psychology and Behaviour. DOI: http://dx.doi. org/10.1016/j.trf.2003.11.003, 7(3): 135-150.

Iversen, H.H.; Rundmo, T. 2004. Attitudes towards traffic safety, driving behaviour and accident involvement among the Norwegian public, Ergonomics. DOI: http://dx.doi.org/10.1080/00140130410001658 709, 47(5): 555-572.

Kontogiannis, T.; Kossiavelou, Z.; Marmaras, N. 2002. Self-reports of aberrant behavior on the roads: errors and violations in a sample of Greek drivers, Accident Analysis and Prevention. DOI: http://dx.doi.org/10.1016/ S0001-4575(01)00035-5, 34(3): 381-399.

Lajunen, T.; Summala, H. 2003. Can we trust self-reports of driving? Effects of impression management on driver behaviour questionnaire responses, Transportation Research PartF: Traffic Psychology and Behaviour. DOI: http://dx.doi. org/10.1016/S1369-8478(03)00008-1, 6(2): 97-107.

Litwin, M.S. 1995. How to Measure Survey Reliability and Validity. Sage Publications, London.

Lund, I.O.; Rundmo, T. 2009. Cross-cultural comparisons of traffic safety, risk perception, attitudes and behavior, Safety Science. DOI: http://dx.doi.org/10.1016/j. ssci.2008.07.008, 47(4): 547-553.

Lund, I. 2006. Attitudes as predictors of driver behaviour in Norway and Ghana. NTNU, Department of Psychology, Trondheim.

Morgan, A.; Mannering, F.L. 2011. The effects of roadsurface conditions, age, and gender on driver-injury severities, Accident Analysis and Prevention. DOI: http:// dx.doi.org/10.1016/j.aap.2011.04.024,43(5): 1852-1863.
National Road Safety Commission (NRSC). 2011. Road Traffic Crashes in Ghana. Statistics 2010. Ministry of Transport, Accra.

Nordfjærn, T.; Jørgensen, S.; Rundmo, T. 2010. An investigation of driver attitudes and behaviour in rural and urban settlements in Norway, Safety Science. DOI: http://dx.doi.org/10.1016/j.ssci.2009.12.001, 48(3): 348-356.

Nordfjærn, T.; Jørgensen, S.; Rundmo, T. 2011. A crosscultural comparison of road traffic risk perceptions, attitudes towards traffic safety and driver behaviour, Journal of Risk Research. DOI: http://dx.doi.org/10.108 0/13669877.2010.547259, 14(6): 657-684.

Nordfjærn, T.; Jørgensen, S.; Rundmo, T. 2012. Cultural and socio-demographic predictors of car accident involvement in Norway, Ghana, Tanzania and Uganda, Safety Science. DOI: http://dx.doi.org/10.1016/j. ssci.2012.05.003, 50(9): 1862-1872.

Odero, W.; Garner, P.; Zwi, A. 1997. Road traffic injuries in developing countries: a comprehensive review of epidemiological studies, Tropical Medicine and International Health. DOI: http://dx.doi. org/10.1111/j.1365-3156.1997.tb00167.x, 2(5): 445460 .

Oltedal, S.T.; Rundmo, T. 2006. The effects of personality and gender on risky driving behaviour and accident involvement, Safety Science. DOI: http:// dx.doi.org/10.1016/j.ssci.2005.12.003, 44(7): 621-628.

Parker, D.; Manstead, A.S.R.; Stradling, S.G.; Reason, J.T. 1992. Determinants of intention to commit driving violations, Accident Analysis and Prevention, 24(2): 117-131.

Parker, D.; Reason, J.T.; Manstead, A.S.R.; Stradling, S.G. 1995. Driving errors, driving violations and accident involvement, Ergonomics. DOI: http://dx.doi. org/10.1080/00140139508925170, 38(5): 1036-1048. 
Peden, M.; Scurfield, R.; Sleet, D.; Mohan, D.; Hyder, A.A.; Jarawan, E.; Mathers, C. 2004. World Report on Road Traffic Injury Prevention. World Health Organisation, Geneva. Available from Internet: <http:// whqlibdoc.who.int/publications/2004/9241562609.pdf $>$.

Poó, F.M.; Ledesma, R.D. 2013. A Study on the Relationship between Personality and Driving Styles, Traffic Injury Prevention. DOI: http://dx.doi.org/10.108 0/15389588.2012.717729, 14(4): 346-352.

Rakauskas, M.E.; Ward, N.J.; Gerberich, S.G.; Alexander, B.H. 2007. Rural and urban safety cultures: human-centered interventions toward zero deaths in rural Minnesota. Human FIRST Program, ITS Institute, University of Minnesota, Minneapolis, MN.

Romano, E.O.; Peck, R.C.; Voas, R.B. 2012. Traffic environment and demographic factors affecting impaired driving and crashes, Journal of Safety Research. DOI: http:// dx.doi.org/10.1016/j.jsr.2011.12.001, 43(1): 75-82.

Russo, F.; Biancardo, S.A.; Dell'Acqua, G. 2013. Road Safety from the Perspective of Driver Gender and Age as Related to the Injury Crash Frequency and Road Scenario, Traffic Injury Prevention. DOI: http://dx.doi. org/10.1080/15389588.2013.794943.

Simon, F.; Corbett, C. 1996. Road traffic offending, stress, age, and accident history among male and female drivers, Ergonomics. DOI: http://dx.doi. org/10.1080/00140139608964497, 39(5): 757-780.

Stanton, N.A.; Salmon, P.M. 2009. Human error taxonomies applied to driving: A generic driver error taxonomy and its implications for intelligent transport systems, Safety Science. DOI: http://dx.doi.org/10.1016/j. ssci.2008.03.006, 47(2): 227-237.

Sullman, M.J.M.; Meadows, M.L.; Pajo, K. 2002. Aberrant driving behaviours amongst New Zealand truck drivers, Transportation Research Part F: Traffic Psychology and Behaviour. DOI: http://dx.doi. org/10.1016/S1369-8478(02)00019-0, 5(3): 217-232.
Ulleberg, P.; Rundmo, T. 2003. Personality, attitudes, and risk perceptions as predictors of risky driving behaviour among young drivers, Safety Science. DOI: http://dx.doi.org/10.1016/S0925-7535(01)00077-7, 41(5): 427-443

Vardaki, S.; Yannis, G. 2013. Investigating the selfreported behavior of drivers and their attitudes to traffic violations, Journal of Safety Research. DOI: http://dx.doi. org/10.1016/j.jsr.2013.03.001, 46(2013): 1-11.

Vlahogianni, E.I. 2013. Modeling duration of overtaking in two lane highways, Transportation Research Part F: Traffic Psychology and Behaviour. DOI: http://dx.doi. org/10.1016/j.trf.2013.07.003, 20(2013): 135-146.

Vlahogianni, E.I.; Golias, J.C. 2012. Bayesian modeling of the microscopic traffic characteristics of overtaking in two lane highways, Transportation Research Part F: Traffic Psychology and Behaviour. DOI: http://dx.doi. org/10.1016/j.trf.2012.02.002, 15(3): 348-357.

Wallén Warner, H.; Åberg, L. 2008. Drivers' beliefs about exceeding the speed limits, Transportation Research Part F: Traffic Psychology and Behaviour. DOI: http:// dx.doi.org/10.1016/j.trf.2008.03.002, 11(5): 376-389.

Yagil, D. 1998. Gender and age-related differences in attitudes toward traffic laws and traffic violations, Transportation Research Part F: Traffic Psychology and Behaviour. DOI: http://dx.doi.org/10.1016/S13698478(98)00010-2, 1(2): 123-135.

Yan, X.; Radwan, E.; Guo, D. 2007. Effects of major-road vehicle speed and driver age and gender on left-turn gap acceptance, Accident Analysis and Prevention. DOI: http:// dx.doi.org/10.1016/j.aap.2006.12.006, 39(4): 843-852.

Yunesian, M.; Mesdaghinia, A.; Moradi, A.; Vash, J.H. 2008. Drivers' knowledge, attitudes, and behaviour: A cross-sectional study, Psychological Reports. DOI: http:// dx.doi.org/10.2466/pr0.102.2.411-417, 102(2): 411-417.

\section{jitte 494}

